\title{
Voices: Exploring the Experiences of Non-Mental Health Professionals Working with Mexican Immigrants Affected by Deportation
}

\author{
Anna Lopez \\ New Mexico State University \\ Ioana Boie \\ Marymount University
}

\begin{abstract}
With large numbers of immigrants living in the United States and a recent increase in deportations, it is imperative that mental health professionals are aware of the implications involved in working with immigrants affected by deportation. The perspectives of non-mental health professionals working with immigrants are valuable in providing insight into the complexity of issues encountered when working with this population. The participants discussed perceptions, reactions, perceived mental health needs, and recommendations for working with Mexican immigrants.
\end{abstract}

Keywords. immigration, deportation, immigrant mental health

\section{Introduction}

According to the Department of Homeland Security, there are an estimated $6,050,000$ "unauthorized" Mexican nationals living in the United States. In 2008, more than 250,000 "unauthorized" Mexican nationals were "removed" from the United States (United States Department of Homeland Security, Yearbook of Immigration Statistics, 2008). Immigrant detention, which is the process an immigrant goes through before deportation, "threatens millions of Latino families and their communities is cause for alarm and further study" (Hernandez, 2008, p. 41). Even though "unauthorized" Mexican immigrants make up a significant percentage of the minority population in this country, only a modest amount of literature has highlighted issues that affect "unauthorized" Mexican immigrants. 
According to Reitmanova and Gustafson (2009), "knowledge about visible minority immigrants" mental health status and needs will inform policy decisions for building a culturally responsive system that effectively addresses determinants of immigrants' well-being and reduces their vulnerability to mental illness" (p. 54). Additionally, the American Counseling Association's (ACA) code of ethics emphasizes the need for counselors to become multi-culturally competent and encourages counselors to "gain knowledge, personal awareness, sensitivity, and skills pertinent to working with a diverse client population" (2005, Standards C.2.a). With the increasing number of people being affected by deportation, it is imperative that counselors gain understanding of the issues this population is experiencing.

With the growing number of immigrants being deported and leaving families behind, it is important for mental health professionals to be prepared to work with this population. As stated by Hixson (2009), "being a psychotherapist or other health care provider requires that we keep abreast of the social changes and needs of change within our lives, the lives of our patients, and in our professional practices" (p. 64). Even though the fields of counseling, psychology, and social work have recently begun to focus on the needs and experiences of immigrants affected by deportation, literature connecting mental health to this topic is limited.

Similarly, a few studies have discussed the experiences of mental health professionals working with immigrants. Existing literature has primarily focused on an overview of potential mental health concerns for documented immigrants and recommendations/suggestions for working with this population. Although the existing literature focused on working with immigrants is invaluable, a discussion of non-mental health professionals' experiences and recommendations may contribute to mental health research and practice.

There are a number of professionals in our community who have years of first-hand experience working with immigrants. Leaders of grassroots organizations, immigration lawyers, educators, and Border Patrol agents, are just a few of the professions with extensive history of working with this population.

The purpose of this qualitative study was to explore perspectives of community professionals who interact with this population. Research focused on this population is necessary in order to better understand and generate necessary interventions for working with Mexican immigrants affected by deportation. Similarly, the experiences of non-mental health professionals in the community who have had a lasting relationship with this population may increase the understanding of the challenges and strategies associated with working with Mexican immigrants affected by deportation issues. Information revealed by this study will hopefully assist in creating more culturally relevant mental health services for this population. Additionally, information revealed by the participants may inform questions and areas of focus for future research.

\section{Method}

Inquiry Approach

A phenomenological inquiry approach was utilized for this study. Participants were interviewed in an effort to obtain a deeper understanding of their experiences working with undocumented 
immigrants. The participants each took part in at least one semi-structured interview. Each interview lasted 45 minutes to 1.5 hours. The overarching question asked to all participants was "What has been your experience working with immigrants affected by deportation?"

\section{Participants}

Participants included two female and three male professionals with experience working with Mexican immigrants affected by deportation. All participants were over the age of 18 and identified themselves as Mexican American. Participants included an immigration attorney, a radio station host, a teacher, a university professor, and a community agency coordinator. Selection of participants from different professions allowed for multiple perspectives to emerge.

Although there was an attempt to include professionals working for different government agencies (ICE, Border Patrol) these professionals declined participation. They reported their unavailability was due to the extensive process of requesting permission for participation from their respective agencies.

\section{The Radio DJ}

Participant has worked as a radio host for five years in a predominantly Mexican/ MexicanAmerican community. His involvement in work with the immigrant population started after his experience hosting an informative radio call-in show on immigration. This participant shared that besides his professional involvement with the immigrant population, his personal experiences of being an immigrant himself allowed him to better relate to his listeners. He estimated that in the last three years he had received phone calls from or been in contact with more than 200 families who he described as "familias que han sufrido por causa de la deportación" [families who have suffered because of deportation].

\section{Community Organization Leader}

This participant has worked with the immigrant population in different capacities since 1975. He described his work with immigrants as one that has been "amplia y en diferentes aspectos" [extensive and different aspects]. He explained that his different roles included filling out immigration applications, Chicano newspaper journalist, teaching ESL classes, among other duties.

\section{Immigration Attorney}

This participant shared that he had been working with immigration cases for several years. Although he shared very limited personal information about himself, he offered extensive information on his clients' struggles surrounding deportation and perceptions of the legal system.

\section{University Professor}

This participant shared having grown up in a large immigrant family. Her professional background included working as a second grade bilingual teacher, working with immigrant children from Mexico and Central America as well as being affiliated with non-profit 
organizations working with undergraduate, first-generation, immigrant students. She continues being involved with immigrant families by doing research revolving around issues associated with immigrant families and school environments.

\section{Teacher}

This participant shared that she had taught at the high school level for four years. She shared that three of the four years had been spent working at a high school in the border city of El Paso, TX. She shared that both her personal and professional experiences with immigration issues have shaped her reactions to her students. Having worked in a border city, she described the experiences working with transnational students.

\section{Results}

The researchers recognize that bias may stem from their own personal experiences with immigration. The researchers recognize that not all immigrants have the same experiences and acknowledge that undocumented status and risk of deportation are additional and considerable stressors in the lives of immigrant families.

\section{Perceptions of the Mexican Immigrant Experience}

Aside from sharing their experiences and personal reaction to working with immigrants affected by deportation, all of the participants also discussed their perception of the Mexican immigrant experience. Although some of the participants mentioned coming from an immigrant background, they each contributed information related to various aspects of the Mexican immigrant life, observed from an outsider's perspective. Most of the interviews focused around the price of immigration, cultural factors affecting the immigrant experience, as well as legal, psychological and social issues related to deportation. These themes will be described in detail in the following section.

\section{Price of Immigration}

The participants shared their thoughts regarding the experiences of Mexican immigrants. Their statements often included the words "sacrifice," "cost," and "price," to explain what is given up by immigrants in coming to the USA. In regards to "the price of immigration," the Community Leader described the factors that contribute to the decision to immigrate to the United States and the consequences attached to it:

the worry, the desperation, the racism and abuse, the discrimination, things that they may be running away from such as misery, hunger, lack of jobs, and to that you add the discrimination and being looked down upon, you are paying for it, and the separation... the price is too high.

Similarly, the Professor emphasized the sacrifice involved in immigrating and stated people don't realize the stress involved with coming to a whole new country. She highlighted the potential stress created by the need for immigrants to adjust to a new house, new school, new city, as well as adjustment to a new language, new values and a new culture. She elaborated by stating that immigrants are often caught in "this middle space," often remembering the 
old country or the way things were ... wishing they were back, and then when they have papers they get to go back and visit, and then they wish they were back over here, they are not really grounded in one single space.

Overall, participants highlighted factors such as racism, discrimination, family separation, and adjustment difficulties associated with migrating to a new country.

\section{Deportation}

The participants shared their thoughts and beliefs regarding the immigrants they work with, and emphasized the devastating consequences of deportation. The most compelling description of the deportation experience was offered by the Community Leader: "el sueño Americano se convierte en una pesadilla" [the American dream becomes a nightmare]. He explained that when a member of the family is deported ["every aspect of life is affected"].

The suffering, anxiety, fear, pain, and trauma that is experienced as a consequence of deportation was highlighted. They all mentioned specific examples of families and their struggles with deportation. Separation of children from parents, spouses from spouses, children being taken by the state, the decision of whether to give up or keep fighting, and the frustration of dealing with the unknown were all identified in their discussions.

\section{Emotional Reactions to Experiences with Families of Deportees}

Equally powerful in the participant's descriptions of the experiences with immigrant families, was their reaction to these stories. There was optimism in their voices that maybe something will happen to make the lives of immigrants better. That enthusiasm faded away as they shared their feelings of powerlessness and inability to create change in the lives of the immigrant families. For example, at the very beginning of the interview, the Immigration Attorney, stated

on a personal level, I don't see myself doing this for $15-20$ years ... because it is very draining; at least in my cases, it can be very draining, emotionally draining, having to deal with the family members who are suffering because either the child, in this case, spouses, spouses are being deported.

When asked to elaborate on what made his work so emotionally draining, he explained that he felt "helpless, I can't do anything, I can't help them, I can't change how the law, it's just very repetitive, I find myself stuck." He later described that so many years of practicing immigration law had made him "become more, not cold, but a fact-finder, the emotional..." His statement was stopped by sudden tears. He continued to talk about having been in this profession for too long and having "paid my dues." He also explained the difficulty of losing cases, and sharing with his clients with some emotion, "Look I can't help you anymore, this is just too tough!" He differentiated the professional and personal challenges in working with this population. The professional challenges he identified revolved around the financial aspect of his profession. He mentioned that although he had been doing as much pro-bono work as possible, he knew that at some point he had to make a "professional financial decision." 
Similarly, the Community Leader stated that the desperation he sees in immigrant families was so great that he could not help but relate to the pain of these families, ["the desperation is then so great, so great, that you can't help but identify with these families' pain"].

The sadness and feelings of impotence were evident during the interview with the Radio DJ. Not realizing how powerful his advocacy for immigrant rights was, the Radio DJ shared his struggle in finding resources for his immigrant listeners. In a tone of voice filled with what seemed to be frustration, the Radio DJ described having limited means of assisting immigrants.

I have had cases when they tell me 'please help me, my children have not eaten since he was deported, and he was deported a week ago;' okay, I can help them, I can send them food, the radio station takes care and worries about a situation like that, but frankly we can't do anything and that is the sad thing.

Similarly, the Professor shared the frustration that she felt when asked for assistance by one of her students shortly after moving to a new city, "I got stressed out, 'how can I help her? I can't believe that I am someone who knows so much about deportation and immigration and I didn't even know here where we could turn to." Her discussion about challenges and reactions to her work with immigrants was overshadowed by her advocacy for this group and her discussion of all the possible issues and challenges that this population encounters. Similarly, the Teacher showed frustration when discussing the difficulties that her students had to go through.

\section{Challenging Moments}

In order to better understand their reactions, the participants were asked to discuss their most challenging or memorable experiences working with immigrants. Many of the stories were filled with dramatic, life-changing experiences. The Community Leader stated that he had a number of memorable stories to choose from because of his wide range of experiences working with immigrants. Although his interview was filled with different challenging moments he had encountered in his career, the following two were discussed in most detail:

The case of a woman whose husband was detained by the police for having tinted windows - that's all, that's why they stopped him. In the moment, they asked for his license and he didn't have one...The police detains him, put him in jail, three days later he was deported, not so much for the tinted windows, but because he was undocumented. But the police themselves are who do the work of Immigration. And after the fact, now what do you do? Five children and the mom by herself. Well this is the case of a woman, has five children, all born here, very young, the children can't do anything for her yet or for their father, because they don't yet have the right to petition for them.

Similarly, the Radio Station DJ shared about his experience helping families in crisis. He shared that one of the most powerful accounts he had encountered was with a family of a Mexican deportee. He described the extent of the pain the deportee's spouse went through as a result of her husband's deportation.

I had a case of one family, one family with three children, and the woman was sick so she couldn't work. The husband got deported, I think there was a police checkpoint and 
he didn't have any warrants or anything and they deported him right there and then, they called Immigration on him and they deported him. The woman called me, she told me that there were days in which she didn't want to live anymore, that instead she wanted to take her life and for her children to go on. Then, in that case, when we are talking about taking one's own life, imagine that, it's a lot, a lot of pain that you feel. So, that is the saddest case that I have had, but not the only one. There are people who want to give up, there are people who don't know what to do.

The Immigration Attorney also discussed various memorable experiences with clients affected by deportation issues. Among those was the case of a family who, aside from facing the consequences of a natural disaster and medical conditions, was in danger of being separated as a result of the mother's undocumented status.

In this particular situation they were in [name of town], their home, their mobile home and their vehicle got destroyed. The parents were in a pick-up truck, the children were in a pick-up truck, their or somebody's mobile home went flying and landed on top of their truck in a hurricane... I mean there isn't a lot of physical damage to the family... but after that they needed therapy because the children would hear rain or loud wind noise and they would run underneath their bed. I mean they were just scared. It was a very traumatic event for them and so they've been going through therapy....and the husband also wasn't in a very good medical condition, has high blood pressure, overweight, diabetic, just a bunch of medical conditions. Well, this is a case that I felt we could win, she got caught, she had no choice but to fight it, or accept the voluntary departure, go back to her country and then wait for the husband to come. But the basis in the theory was why separate them even for a month or two or three months because if you do the children are already suffering...

The Teacher discussed transnationalism, which had not been explored in any of the other participants' stories. She elaborated on what it was like for her students to cross the border every day. The Teacher vividly described her students' fear of deportation. In her discussion of the most difficult experiences with people affected by deportation, the Teacher shared the story of a boy, who encountered many challenging situations that most children never come across in their lives.

I remember one [student] in specific, he would always come late in the mornings and I would always get on his case for coming in late. And then I found out that he was living at home with his mom in Mexico because that's the only way he could see them and every single day he was crossing the bridge, and he had to get a bus from the bridge to the school. And then I started realizing 'okay I'm not gonna get mad at him because I can imagine at what time he leaves every morning and what time he has to get up.' Another thing that happened to him because this was in Juarez is that one day he came beat up to school and umm I kinda asked him because I thought it was something at the school or gang related or girl related and no, he said he was just walking home from school and that the way things are in Juarez they jumped him for no reason, he had nothing they could away from, he had no phone and no wallet. Just having to deal with that every day. 
Although the Professor's focus appeared to be on the overall effect of immigration and deportation, she briefly described one of the most difficult experiences faced by one of her graduate students.

I have a person who's a teacher who has her residency... and she married someone who was undocumented and he was deported, and she's still a full-time teacher so she's doing her master's degree ... she sees this in her own class with bilingual kids and she's the one whose spouse was sent ....something we get is - 'is there a lawyer I can talk to? Do we have any rights, or you know, how can we maintain contact with them?' So just like trying to process what are the next steps with that.

\section{Perceived Mental Health Needs of Mexican Immigrants}

It was not surprising to find that the participants had similar perceptions regarding the mental health needs of immigrants challenged by issues related to deportation. Trauma, depression, anger, and issues related to family separation were all highlighted. Suicidal ideation, drug use, and anxiety were also mentioned. Additionally, one of the participants shared concern over the possible behavioral changes in the children of deportees. Although all participants were very insightful about this topic, there was an apparent hesitation, usually followed by statements indicating their perceived lack of knowledge regarding mental health issues. Their discussions on the topic, however, illustrated a vivid picture of the potential mental health needs of the immigrant population:

The trauma is very powerful, the desperation is very powerful, the problems with worry are very powerful, so people get discouraged ... they can get to their limit, to suicide or drugs, or go to the extreme; it can lead to the woman prostituting herself to provide food for her children, things that had never even crossed their mind before.

\section{Perceived Importance of Mental Health Services}

Their discussion of perceived mental health needs was followed by statements regarding the importance of counseling services. All five participants stated that counseling/therapy was invaluable. The Immigration Attorney stated "I think therapy, I think the wife and the children, needing counseling, talking to someone about the fact that they're separated from their father." The Radio DJ stated

But when we are speaking psychologically, one doesn't know what they are going through. Like I'm telling you, there was a lady that would rather take her own life. Then when you are dealing with a counselor that has the tools that could talk to them and help them change their negative thoughts, I think that it is very important, that there should be a lot of those [counselors] because there are a lot of people who need them.

Other participants also emphasized ways in which they believed counseling could best assist this population. Assistance with decision-making was considered important to the participants because immigrants challenged by deportation issues typically encounter a number of decisions including whether to join spouse in Mexico or stay in the U.S., leave their children or take them, who to leave children with, whether to take legal action, among others. The participants 
mentioned other strategies, such as normalizing the situation to help clients understand that "this has happened to other people." The participants agreed that the role of mental health professionals extended beyond the emotional and psychological needs of this population. They also emphasized the importance connecting clients with resources and disseminating accurate information regarding the immigration and deportation processes.

\section{Participant Recommendations}

\section{Breaking Barriers}

Recommendations for how mental health professionals can improve the lives of families affected by deportation were embedded in the participants' stories. One of them highlighted that because the immigrant families do not qualify for any services, oftentimes they have to get their mental health needs taken care through the private sector. Tied to these needs and the perceived limited or lack of availability of services, the Immigration Attorney's recommendation was to address the need for mental health care through "more non-profits helping the illegal for the mental-health needs."

The participants agreed that although there is a perception that the immigrant population is not interested in mental health services, it is the delivery of these services that forms the barrier between immigrants and health care professionals. The fear of deportation and lack of approachability were among the obstacles identified. The Community Leader called for a change in marketing strategies in order to better fit the cultural expectations of the immigrant population. More specifically, the Community Leader suggested that mental health professionals have a greater presence in the immigrant community instead of expecting individuals to trustingly walk through their doors. He further emphasized the need for mental health professionals to become more approachable to these clients by focusing on developing trust.

\section{Understanding Contextual Factors}

One of the main recommendations provided by the participants was the need for mental health professionals to develop an understanding of the cultural context of this population. The Professor talked about the value of mental health professionals understanding the contextual issues their immigrant clients are facing, at home and in the society. She emphasized that her advice would be for "counselors to think about the context." This is important as it shifts the focus from the clients' internal processes and responsibility to a better understanding and working with the client's contextual challenges which affect their wellbeing.

Similarly, the Community Leader shared that even though education and training have their value, oftentimes traditional counseling approaches might be insufficient. He stated

If you all take into account the ... 'ethnic origin' of the person and you understand it and analyze it and know all the cultural factors, all the linguistic factors and the socioeconomic factors of those people, and you know them well then you will be able to help them. But if you don't, if you are going to use the methods written in books you will not be able to help them much because the book can say interesting and technically complicated things, but at the moment you apply it, you throw away this book it won't 
help you, it might serve you as a guide or methodology to attend to the client, but you have to understand the socio-economic origin perfectly, the ethnic origin of the people also, or the origin of the community they come from, their customs.

The Professor also suggested paying attention to contextual matters, including a good understanding of the ways in which the practitioner's own background and values impact the counseling process. She stated that

the local context matters or sometimes it's the individual. This one woman or this man is facing this because of her or his household situation, so it's very particular compared to the other Mexican immigrants who come to my office. Or counseling center, right? So sometimes it's the individual situation that doesn't have anything to do with the context. But, of course, the counselor has to be aware. But look at me, I'm a PhD, Latina, like when I went to seek counseling, I was always trying to find it with someone who is bilingual and bicultural because I didn't want to hear the counselor telling me her perspective on my issue; and I know they're all trained but they don't have the context of being Latina or understanding that.

In the context of recommending for counselors to be more aware and understanding of the contextual issues influencing the immigrant families, she also suggested developing a program, such as a certificate in conjunction to the counseling program.

to create a certificate for the counseling program. You know, there's like 5 courses that are 3 hours each at the master's level that help counselors work with bilingual bicultural immigrant populations. So what would help me? I've learned all this new training but now how do I apply it to this specific setting? So one could be about the history of (city where interviews took place), one could be about the immigration, one could be about the Latino family.

Furthermore, the Immigration Attorney stated that mental health professionals should have basic knowledge of immigration laws as well as understanding of the context and conditions. He stated that it would be helpful to know

how to help them? How to talk to them? And maybe understanding the dynamics, and maybe that's beyond what you all should do, but understanding the dynamics of how immigration law works ...I think being familiar with the maybe the terminology, not giving them legal advice, or telling them how to come back, or I don't know, maybe understanding country conditions on the other side, understanding the news, the reports...

\section{Advocacy}

The Immigration Attorney also recommended that school counselors be advocates for the education of immigrant children, including higher education opportunities. He stated that "if you can capture the parents and the children at a young age, regardless of their status, whether it's legal or illegal, and focusing on education, getting educated. Making sure that they understand they have economic voting power and that they should use and they should exert that power. I think there, start there that would be great!" 


\section{Discussion}

Taking an interdisciplinary approach to revealing the experiences of marginalized populations enriches our understanding of the issues faced by these individuals through the lens of various professions. Integrating the stories of individuals from various professions provided a rich picture of the most salient issues and challenges that may arise when working with individuals affected by deportation. With large number of immigrants living in the United States and the recent increase in deportation occurrences, it is imperative that mental health professionals are aware of the implications involved in working with immigrants affected by deportation. The perspectives of professionals who have a long history of working with immigrants may be valuable in providing counselors with an increased awareness of the complexity of issues and challenges that may be encountered when working with this population.

Although the participants each played a different role in the lives of Mexican immigrants, all of them appeared to be passionate about their work. Their passion came across in their detailed examples of challenges encountered, but most evident in their description of the perceived difficulties encountered by the people they touched with their work. Each in their own way, the participants shared the duties they fulfilled in working with Mexican immigrants, each extending their professional responsibilities to include advocacy. Their stories provided vivid illustrations of both their professional experiences with Mexican immigrants as well as their personal reactions to these experiences.

Among the most common themes obtained from the interviews were the professionals' perceptions of the Mexican immigrant experience, detailed stories of their work with specific students, clients, and listeners, reactions to their work with Mexican immigrants, and perceived mental health needs of Mexican immigrants who have been affected by deportation.

All the participants also provided recommendations for practitioners working with Mexican immigrants affected by deportation. One of the unexpected findings was the similarity in the participants' experiences, challenges, and recommendations for practice. Although their professions involved unique tasks, all of them assumed an advocacy role.

\section{Implications for Mental Health Professionals}

Congruent with the recommendations provided by the participants, Nikelly (1997) highlighted the importance of developing a trusting relationship. Similarly, Cervantes, Mejia and Mena (2010) highlighted the importance of building a trusting therapeutic relationship and suggested that building an alliance with the client is critical with respect to disclosure of issues related to immigrant status, family separation and pressures associated with deportation.

Nikelly (1997) also suggested that working with immigrants requires counselors to utilize practical approaches such as assistance in finding jobs and appropriate housing. Because of the nature of the issues confronted by this population, psycho-educational approaches may be more effective than "analytical, psychodynamic, and insight-oriented therapies" (p. 229). More specifically, Nikelly (1997) stated that "most effective and appropriate for this group [immigrants] would seem to be a structured, directive yet supportive approach that is reality oriented and emphasizes problem solving and common sense" (p. 230). 
In regards to breaking the perceived barriers that are keeping immigrants from making use of mental health services, practitioners, educators, and researchers should work together in an effort to identify methods for increasing "approachability" whether it is through the use of different marketing strategies or alternate service delivery methods (i.e., offering counseling services at established community centers, churches, or schools). Furthermore, mental health professionals could benefit by being an integral part of community organizations providing services to immigrant families through collaboration with other non-mental health professionals.

In an effort to address the contextual factors highlighted by the participants, mental health providers should receive additional training in order to obtain a better understanding of the immigrant experience. Additionally, aside from contextual issues, practitioners should also invest in becoming more proficient in their ability to communicate in Spanish. According to Cervantes, Mejia and Mena (2010), practitioners need to be increasingly more proficient in both their ability to communicate in Spanish as well as cultural skills necessary to provide both appropriate assessment and treatment in this language.

As recommended by the University Professor, educators in mental health training programs could assist their communities in different ways such as developing a certification for working with bilingual bicultural clients. In addition, training programs could include immersion experiences for counselors-in-training to facilitate a better understanding of contextual challenges faced by immigrant in their communities. Finally, as recommended by Cervantes, Mejia and Mena (2010), because the topic of immigration creates such an array of attitudes and reactions, it is imperative for both mental health professionals as well as professionals in training to reflect on any unexamined feelings or biases that may affect consultation, supervision, or treatment of undocumented immigrants and their families.

\section{Conclusion}

Although there is an increased interest regarding factors that contribute to immigrants' mental health, little attention has been given to the psychological needs of Mexican immigrants affected by deportation. Research focused on this population is necessary in order to better understand and generate appropriate interventions for working with Mexican immigrants affected by deportation. Similarly, experiences of professionals with a history of working with this population may identify potential challenges and provide recommendations for working with this population. Furthermore, it is important that educators and mental health training programs offer additional training in multiculturalism to those students interested in working with this population.

Contact information:

Anna Lopez

Assistant Professor, New Mexico State University

Email: anna_3329@yahoo.com 


\section{References}

American Counseling Association (2005). ACA Code of Ethics. Alexandria, VA: Author.

Cervantes, J. M., Mejia, O. L., \& Mena, A. G. (2010). Serial migration and the assessment of extreme and unusual psychological hardship with undocumented Latina/o families. Hispanic Journal of Behavioral Sciences, 32(2), 275-291. doi: $10.1177 / 0739986310366286$

Creswell, J. W. (2007). Qualitative inquiry and research Design: Choosing among five approaches. Thousand Oaks: Sage.

Espinoza, L. (1990). Masks and other disguises: Exposing legal academia. Harvard Law Review, 103, 1878-1886. doi:10.2307/1341322.

Garcia, R. (1995). Critical race theory and Proposition 187: The racial politics of immigration law. Chicano-Latino Law Review, 17, 118-148.

Hernandez, D. M. (2008). Pursuant to deportation: Latinos and immigrant detention. Latino Studies, 6, 35-63.

Hernandez-Truyol, B. (1997). Borders (en)gendered: Normativities, Latinas and a LatCrit paradigm. New York University Law Review, 72, 882-927.

Hixson, R. (2009). When social change isn't fast enough to prevent pain and death. American Psychotherapy Annuals, 64-66.

Johnson, K. (1997). Some thoughts on the future of Latino legal scholarship. Harvard Latino Law Review, 2, 101-144.

Nikelly, A. G. (1997). Cultural babel: The challenge of immigrants to the helping professions. Cultural diversity and Mental Health, 3(4), 221-233.

Reitmanova, S., \& Gustafson, D. L. (2009). Mental health needs of visible minority immigrants in a small urban center: Recommendations for policy makers and service providers. Journal of Immigrant Minority Health, 11, 46-56. DOI: 10.1007/s10903-008-9122-x.

Solorzano, D. \& Delgado Bernal, D. (2001). Examining transformational resistance through a critical race and LatCrit theory framework: Chicana and Chicano students in an urban context. Urban Education, 36, 308-342.

Tierney,W. (1993). Building communities of difference: Higher education in the twenty-first century. South Hadley, MA: Bergin and Garvey.

United States. Department of Homeland Security. Yearbook of Immigration Statistics: 2008. Washington, D.C.: U.S. Department of Homeland Security, Office of Immigration Statistics, 2009. 